\title{
EVIDENCE ON PURCHASING POWER PARITY FROM UNIVARIATE MODELS: THE CASE OF SMOOTH TRANSITION TREND-STATIONARITY
}

\author{
Robert Sollis ${ }^{1}$ \\ Department of Economics and Finance, University of Durham
}

\begin{abstract}
SUMMARY
Recent research has found that trend-break unit root tests derived from univariate linear models do not support the hypothesis of long-run purchasing power parity (PPP) for U.S. dollar real exchange rates. In this paper univariate smooth transition models are utilised to develop unit root tests that allow under the alternative hypothesis for stationarity around a gradually changing deterministic trend function. These tests reveal statistically significant evidence against the null hypothesis of a unit root for the real exchange rates of a number of countries against the U.S. dollar. However, restrictions consistent with long-run PPP are rejected for many of the countries for which a rejection of the unit root hypothesis is obtained.
\end{abstract}

\footnotetext{
${ }^{1}$ Address: Robert Sollis, Department of Economics and Finance, University of Durham, 23-26 Old Elvet, Durham, DH1 3HY, United Kingdom.

Tel: 44 (0)191 3747282 Fax: 44 (0)191 3747289 E-mail: Robert.Sollis@durham.ac.uk
} 


\section{INTRODUCTION}

A vast amount of empirical research has been carried out on the purchasing power parity (PPP) hypothesis employing the unit root and cointegration methodology. The early work in this area, using conventional Dickey-Fuller-type unit root tests, found that for U.S. dollar real exchange rates the unit root hypothesis could not be rejected, implying the absence of PPP. This failure to reject the unit root hypothesis has been attributed to the low power of the tests used for the sample sizes involved, and many empirical investigations of real exchange rate behaviour now favour more powerful panel data unit root tests (see Wu, 1996; Papell, 1997; Papell, 2002). Another group of studies consists of those that have allowed for the effects of transaction costs on the behaviour of real exchange rates (see Michael et al., 1997; Taylor et al., 2001; Sollis et al., 2002). These studies are motivated by the argument that, due to the presence of transaction costs, arbitrage may not be profitable for small price differentials but is profitable for larger price differentials. Consequently the degree of mean reversion of real exchange rates is weak when real exchange rates are close to their long-run mean and increases as they move away from their long-run mean. The empirical work on this issue has focused on capturing changes in the degree of mean reversion of real exchange rates as a result of the effects of transaction costs using non-linear models, and it is generally found that allowing for non-linear mean reversion when testing for a unit root in real exchange rates does tend to reveal more evidence against the unit root hypothesis than conventional tests derived from linear models.

Recent research by Papell (2002) focuses on the possibility that for quarterly U.S. dollar real exchange rates, the dramatic nominal appreciation and depreciation of 
the dollar in the 1980s should be modelled as breaks in a deterministic trend. Using the procedure developed by Bai (1999), Papell (2002) finds statistical support for the hypothesis of three-breaks. However, univariate unit root tests incorporating a deterministic trend with three breaks do not reveal rejections of the unit root null, although rejections are obtained for some groups of countries from panel data tests allowing for multiple trend-breaks. In this paper we also focus on the issue of structural change in deterministic trends in U.S. dollar real exchange rates. Rather than model trend-breaks using the dummy variable approach, here, univariate smooth transition (STR) models are employed that allow for non-monotonic smooth transitions in the trend function of the data generation process (DGP). Employing new tests derived from these non-linear models, we find that the null hypothesis of a unit root can be rejected in favour of the hypothesis of stationarity around a smooth transition in the deterministic trend for many of the twenty countries examined by Papell (2002). The bulk of the nonlinearity in the model for each of these series corresponds to the appreciation and depreciation of the dollar in the 1980s.

These results reveal support for the trend-stationarity hypothesis, however, for many of the countries for which rejections of the unit root hypothesis are obtained from our new tests, there are deterministic trends in the pre-appreciation and postdepreciation periods. Therefore, despite being able to reject the null hypothesis of a unit root in favour of stationarity around a gradually changing trend function, for these countries, strictly we cannot conclude that the evidence supports the hypothesis of longrun PPP, since as Papell (2002) points out, that requires the real exchange rate to have an equal, constant mean before and after the structural change. 
Since the seminal work of Teräsvirta (1994) and Lin and Teräsvirta (1994), smooth transition models have become increasingly popular. In addition to empirical investigations of real exchange rates, the many applications of smooth transition models to economic and financial time series include investigations of industrial production and the business cycle (see Teräsvirta and Anderson, 1992; Granger and Teräsvirta, 1993; Teräsvirta et al., 1994; van Dijk and Franses, 1999), interest rates (Anderson, 1997; van Dijk and Franses, 2000), and the money-output relationship (Rothman et al., 1999; Swanson, 1999). Many of the empirical applications of smooth transition models have involved versions that assume the structure of the model changes as a function of a lag of the dependent variable - known as smooth transition autoregressive (STAR) models. The STR models that we employ differ to STAR models as we consider continuous change in the parameters of the deterministic trend function in the DGP for real exchange rates as a function of time. Leybourne et al. (1998) have developed tests of the null hypothesis of a unit root allowing for this type of structural change under the alternative hypothesis. However, since these tests only allow for a single monotonic transition in the trend function, they are not appropriate for the case of multiple breaks. For the analysis in this paper the monotonic single break tests are extended to nonmonotonic versions that capture three gradual breaks (or four regimes: pre-appreciation, appreciation, depreciation and post-depreciation). Critical values for our new tests are simulated using Monte Carlo procedures and a number of simulation experiments undertaken to investigate the size and power of the new tests.

The plan of the rest of the paper is as follows; in Section 2 the monotonic single transition unit root tests proposed by Leybourne et al. (1998) are briefly outlined and in Section 3 these tests are extended to the case of non-monotonic transitions. In Section 4 
the size and power of the new tests is considered and Section 5 discusses the application of the tests to quarterly data on U.S. dollar real exchange rates for twenty countries. Section 6 concludes.

\section{TESTS FOR A UNIT ROOT WITH MONOTONIC SMOOTH TRANSITIONS}

Leybourne et al. (1998) propose unit root tests that use STR models to allow under the alternative hypothesis for stationarity around an endogenously determined smooth transition in the deterministic components of a time series. They consider three cases; a transition in the intercept of a non-trending time series, a transition in the intercept of a trending time series, and a transition in the intercept and slope of a trending time series. The three relevant models are;

$$
\begin{aligned}
& y_{t}=\alpha_{1}+\alpha_{2} S_{t}(\gamma, c)+v_{t} \\
& y_{t}=\alpha_{1}+\beta_{1} t+\alpha_{2} S_{t}(\gamma, c)+v_{t} \\
& y_{t}=\alpha_{1}+\beta_{1} t+\alpha_{2} S_{t}(\gamma, c)+\beta_{2} t S_{t}(\gamma, c)+v_{t}
\end{aligned}
$$

where $v_{t}$ is a zero-mean $\mathrm{I}(0)$ process and $S_{t}(\gamma, c)$ is the logistic function for a sample of size $T$,

$$
S_{t}(\gamma, c)=(1+\exp \{-\gamma[t-c T]\})^{-1}, \quad \gamma>0
$$


which monotonically traverses the interval $(0,1)$ as $t \rightarrow \infty$. The mid-point of the transition is determined by the parameter $c$, since $S_{c T}(\gamma, c)=0.5$. The speed of the transition is determined by the parameter $\gamma$. Note that for small values of $\gamma, S_{t}(\gamma, c)$ moves gradually from 0 to 1 , whilst for large values of $\gamma, S_{t}(\gamma, c)$ moves from 0 to 1 very rapidly, and as $\gamma$ approaches $+\infty$ this function changes value from 0 to 1 almost instantaneously. If $\gamma=0, S_{t}(\gamma, c)=0.5$ for all $t$ and thus the non-linear models (1), (2) and (3) nest linear trends.

The models (1), (2) and (3) can be used to test the following hypotheses;

$$
\begin{aligned}
& H_{0}: y_{t}=\mu_{t}, \mu_{t}=\mu_{t-1}+\varepsilon_{t} \\
& H_{1}:(1),(2) \text { or (3) } \\
& H_{0}: y_{t}=\mu_{t}, \mu_{t}=\kappa+\mu_{t-1}+\varepsilon_{t} \\
& H_{1}:(2) \text { or (3) }
\end{aligned}
$$

where $\varepsilon_{t}$ is assumed to be a stationary process with zero mean. In both cases, under the null hypothesis $y_{t}$ contains a unit root. Leybourne et al. (1998) propose a two-step procedure for calculating the statistics for testing these hypotheses. The first step involves estimating the deterministic component of the relevant model by non-linear least squares (NLS) and computing the NLS residuals $\hat{v}_{t}$. The second step involves computing the $t$-statistic for testing the null hypothesis of a unit root in $\hat{v}_{t}$. In Leybourne et al. (1998) the statistics associated with models (1), (2), and (3) are 
referred to as $s_{\alpha}, s_{\alpha(\beta)}$ and $s_{\alpha \beta}$ respectively. The non-linear models (1), (2), and (3), are linear in the parameters $\alpha_{1}, \beta_{1}, \alpha_{2}$ and $\beta_{2}$, and Leybourne et al. (1998) exploit this feature to simplify the estimation of these models by concentrating the NLS sum of squares function with respect to $\alpha_{1}, \beta_{1}, \alpha_{2}$ and $\beta_{2}$ so that the NLS estimation reduces to minimizing the sum of squares function with respect to just the two parameters $\hat{\gamma}$ and $\hat{c}$. Since the non-linearity of the model makes it virtually impossible to establish the analytical relationship between $\hat{v}_{t}$ and $y_{t}$, the null distribution of the test statistics is determined using Monte Carlo simulation.

\section{TESTS FOR A UNIT ROOT WITH NON-MONOTONIC SMOOTH TRANSITIONS}

While the unit root tests proposed by Leybourne et al. (1998) have proved to be useful for the analysis of economic times series (see Leybourne et al., 1998; Mizen and Leybourne, 1999), the fact that the models only allow for a single monotonic transition in the trend function is restrictive. When investigating the presence of breaks in the trend function of real exchange rates, Papell (2002) finds that for the majority of countries in the sample, three breaks is appropriate, corresponding to the dramatic appreciation and depreciation of the dollar in the 1980s. The logistic function based STR models proposed by Leybourne et al. (1998) are unable to capture more than one break. In this section we extend the models and tests proposed by Leybourne et al. (1998) to the case of an exponential smooth transition, designed to capture the three breaks in the trend function of real exchange rates.

Consider the following STR models, 


$$
\begin{aligned}
& y_{t}=\alpha_{1}+\alpha_{2} E_{t}(\gamma, c)+v_{t} \\
& y_{t}=\alpha_{1}+\beta_{1} t+\alpha_{2} E_{t}(\gamma, c)+v_{t} \\
& y_{t}=\alpha_{1}+\beta_{1} t+\alpha_{2} E_{t}(\gamma, c)+\beta_{2} t E_{t}(\gamma, c)+v_{t}
\end{aligned}
$$

where $v_{t}$ is a zero-mean $\mathrm{I}(0)$ process and $E_{t}(\gamma, c)$ is the exponential function

$$
E_{t}(\gamma, c)=\left(1-\exp \left\{-\gamma^{2}[t-c T]^{2}\right\}\right)
$$

which traverses the interval $(0,1)$ as $(t-c T) \rightarrow \pm \infty$, and is symmetric around zero. The parameters $\gamma$ and $c$ determine the speed and timing of the transition respectively, and for large values of $\gamma$ the function $E_{t}(\gamma, c)$ resembles an impulse dummy that switches from $1(t<c T)$ to $0(t=c T)$ and back to $1(t>c T)$. As in the case of the logistic STR model, the parameters of the exponential STR (ESTR) models (5), (6) and (7) can be estimated using a conventional numerical optimisation algorithm.

It is not immediately clear that ESTR models are appropriate for the analysis of real exchange rates when there are three breaks in the trend function, however, to clarify, in Figure 1(a) and 1(b) two simulated realisations of 100 observations assuming as a DGP the ESTR model (7), (8) are given. In both cases $y_{t}$ is plotted along with the relevant trend functions. The first realisation (labelled DGP 1) is generated assuming the following parameter values; $\alpha_{1}=1, \beta_{1}=0.2, \alpha_{2}=1, \beta_{2}=-0.25, \gamma^{2}=0.01$, $c=0.5$. Thus, the series generated contains a deterministic trend with a negative slope as $(t-0.5 T) \rightarrow \pm \infty$ (since $\left.\beta_{1}+\beta_{2}<0\right)$. The second realisation (labelled DGP 2) is generated by the same model with the following parameter values; $\alpha_{1}=1, \beta_{1}=0.2$, 
$\alpha_{2}=1, \beta_{2}=-0.2, \gamma^{2}=0.01, c=0.5$. Therefore in this case there is no trend as $(t-0.5 T) \rightarrow \pm \infty\left(\right.$ since $\left.\beta_{1}+\beta_{2}=0\right)$. In both DGPs these parameter values generate a rise and fall in the trend function of the DGP in the middle of the sample akin to the pattern of structural change in dollar-based real exchange rates. Given in Figure 1(c) is the real exchange rate for the Norwegian krone against the U.S. dollar. The trend pattern in the series generated by these DGPs compares very closely with the trend in the real exchange rate series given, and clearly the exponential function is able to capture the four regimes; pre-appreciation, appreciation, depreciation and post-depreciation. ${ }^{2}$

By using the exponential function (8) to model the effects of the appreciation and depreciation of the dollar we are assuming symmetry in the rise and fall of the real exchange rate around a transition mid-point. This assumption may be overly restrictive. It is possible to relax this assumption in our empirical models by making use of a 'switching' version of the exponential function. Consider the following such function:

$$
S E_{t}\left(\gamma_{1}, \gamma_{2}, c\right)=\left(1-\exp \left\{-I_{t} \gamma_{1}^{2}[t-c T]^{2}-\left(1-I_{t}\right) \gamma_{2}^{2}[t-c T]^{2}\right\}\right)
$$

where $I_{t}=1$ if $t-c T \leq 0$ and 0 otherwise. The function $S E_{t}\left(\gamma_{1}, \gamma_{2}, c\right)$ traverses the interval $(0,1)$ as $(t-0.5 T) \rightarrow \pm \infty$, and if $\gamma_{1} \neq \gamma_{2}$ the transition speed of $S E_{t}\left(\gamma_{1}, \gamma_{2}, c\right)$ is asymmetric either side of the mid-point $c T$. Up until $c T$, the speed of the transition is determined by the value of $\gamma_{1}$, while after $c T$ through to the end of the sample the

\footnotetext{
${ }^{2}$ While the exponential function is employed in this paper, there are a number of ways that multiple breaks could be modelled using the smooth transition methodology, see for example the higher-order logistic function utilised by Lin and Teräsvirta (1994). We experimented with this function and with the use of double smooth transition models proposed by Harvey and Mills (2002), however, for the real exchange rate data examined in this paper the exponential function was preferred in terms of model fit (on the basis of the Schwarz criterion), and in terms of the number of rejections of the unit root hypothesis revealed.
} 
speed of the transition is determined by the value of $\gamma_{2}$. In Figure 1(d) 100 observations of a series generated from (7) but with $E_{t}(\gamma, c)$ replaced by $S E_{t}\left(\gamma_{1}, \gamma_{2}, c\right)$ are plotted (labelled DGP 3) assuming the following parameter values; $\alpha_{1}=1, \beta_{1}=0.2, \alpha_{2}=1$, $\beta_{2}=-0.2, \gamma=0.01, c=0.5, \gamma_{1}^{2}=0.005, \gamma_{2}^{2}=0.1$. In this case the deterministic trend undergoes a slow upwards transition and much more rapid downwards transition. Note that asymmetric transition models employing (9) nest symmetric transition models employing (8), since a symmetric exponential transition occurs when $\gamma_{1}=\gamma_{2}$. Replacing $E_{t}(\gamma, c)$ with $S E_{t}\left(\gamma_{1}, \gamma_{2}, c\right)$ in (5) and (6) yields asymmetric versions of these models. To distinguish between the symmetric and asymmetric models, the latter will be refereed to as SESTR (switching exponential smooth transition) models.

Having proposed ESTR and SESTR models for the analysis of real exchange rates in the presence of three breaks, we now consider testing the null hypothesis of a unit root against the alternative hypothesis of stationarity around ESTR and SESTR trend functions. The approach used by Leybourne et al. (1998) can be employed. Consider the general ESTR model given by (7); that is, a model which allows for an exponential smooth transition in the intercept and deterministic trend of the DGP (analogous to Model C in Leybourne et al., 1998). This model can be used to test the following hypotheses;

$$
\begin{aligned}
& H_{0}: y_{t}=\mu_{t}, \mu_{t}=\mu_{t-1}+\varepsilon_{t} \\
& H_{1}:(7) \\
& H_{0}: y_{t}=\mu_{t}, \mu_{t}=\kappa+\mu_{t-1}+\varepsilon_{t}
\end{aligned}
$$


As before, the testing procedure involves two steps. Firstly, estimate the deterministic component of the model using NLS and compute the NLS residuals,

$$
\hat{v}_{t}=y_{t}-\hat{\alpha}_{1}-\hat{\beta}_{1} t-\hat{\alpha}_{2} E_{t}(\hat{\gamma}, \hat{c})-\hat{\beta}_{2} t E_{t}(\hat{\gamma}, \hat{c})
$$

Then, compute the $t$-statistic for testing $\rho=0$ in the autoregressive model

$$
\Delta \hat{v}_{t}=\rho \hat{v}_{t-1}+\sum_{i=1}^{k} \delta_{i} \Delta \hat{v}_{t-i}+\eta_{t}
$$

Henceforth, we refer to this test as $e_{\alpha \beta} \cdot{ }^{3}$ Using the ESTR models (5) and (6) this twostep approach can be applied to derive analogous tests to $s_{\alpha}$ and $s_{\alpha(\beta)}$, which we will refer to as $e_{\alpha}$ and $e_{\alpha(\beta)}$, and SESTR versions of all three tests: $a e_{\alpha}, a e_{\alpha(\beta)}$, and $a e_{\alpha \beta}$.

The linearity property of the various models means that critical values for these tests can be obtained by Monte-Carlo simulation under the null hypothesis of a random walk with no drift (see Leybourne et al., 1998). Hence the following null DGP was used;

$$
y_{t}=\mu_{t}, \quad \mu_{t}=\mu_{t-1}+\varepsilon_{t}, \quad \varepsilon_{t} \sim \operatorname{NID}(0,1),
$$

\footnotetext{
${ }^{3}$ Again, note that as in the case of the logistic STR model, the estimation of ESTR and SESTR models can be simplified by concentrating the sum of squares function with respect to the non-linear parameters $\gamma\left(\gamma_{1}, \gamma_{2}\right)$ and $c$.
} 
with $\varepsilon_{t}$ generated using the random number generator in GAUSS Version 3.2. The critical values, based on 10,000 replications, are given in Table I. Comparing these critical values with those for the conventional Dickey-Fuller (DF) unit root tests (Dickey and Fuller, 1979), as expected, the critical values for these new tests are considerably more negative.

\section{SIZE AND POWER}

In this section we begin by reporting the results of some simple experiments to investigate the size of the proposed tests. When undertaking tests such as the ESTR and SESTR tests proposed in this paper, investigating the robustness of the simulated critical values to different specifications under the null and alternative hypothesis is important. This is particularly true here since in the empirical investigation below, overfitting or under-fitting of additional lagged changes at the second step of the testing procedure may occur. The following ARIMA $(1,1,0)$ model was employed as a DGP;

$$
\begin{aligned}
& y_{t}=\mu_{t} \\
& \Delta \mu_{t}=\phi \Delta \mu_{t-1}+\varepsilon_{t} \quad \varepsilon_{t} \sim \operatorname{NID}(0,1) .
\end{aligned}
$$

We simulated from this DGP for parameter values $\phi=0, \phi=-0.4, \phi=0.4$, and computed the size of the $e_{\alpha}$ test for different values of $k(0,1$, and 4$)$ in step-two of the testing procedure. Thus, for $\phi=0$ the correct value of $k$ when carrying out the $e_{\alpha}$ test is 0 , and for $\phi \neq 0$ the correct value for $k$ is 1 . The results are given in Table II for the 
sample sizes $T=100$, and $T=200$, and in each case 1,000 replications were used. Similar to the findings of Leybourne et al. (1998) for their logistic based tests, we find that for $T=100$, under-fitting the number of lags leads to large size distortions. In particular the test is over-sized in the case of $\phi=-0.4$ and under-sized for $\phi=0.4$. While over-fitting the number of lags leads to some size distortion (the tests are marginally under-sized), the problem is less serious. When the correct specification is used the empirical size of the test is close to the nominal size. A similar pattern is found for the larger sample $T=200$, although generally when an over-fitted model is used the tests are marginally over-sized rather than marginally under-sized.

For the sake of brevity, in Table II we only report results for $e_{\alpha}$. However, experimentation with the other tests proposed in this paper confirms that the results reported in Table II are representative of the other test statistics. As with the conventional augmented Dickey-Fuller (ADF) test, the ESTR (SESTR) tests appear to have good size properties when the correct specification is used and if the model is over-fitted, but there are size distortions if an under-fitted model is employed.

The next set of experiments are concerned with the power of the new tests. Firstly we examine the power of both $e_{\alpha \beta}$ and the DF test $\tau_{\tau}$ for a stationary process around an exponential smooth transition in the deterministic trend function. The following model was employed as a DGP;

$$
\begin{aligned}
& y_{t}=\alpha_{1}+\beta_{1} t+\alpha_{2} E_{t}(\gamma, c)+\beta_{2} t E_{t}(\gamma, c)+v_{t} \\
& E_{t}(\gamma, c)=\left(1-\exp \left\{-\gamma^{2}[t-c T]^{2}\right\}\right) \\
& v_{t}=\phi v_{t-1}+\eta_{t}
\end{aligned}
$$




$$
\eta_{t} \sim N I D(0,1)
$$

Therefore $e_{\alpha \beta}$ is the correctly specified test. All combinations of the following parameter values were used in generating series of 100 observations in length from this model;

$$
\begin{aligned}
& \alpha_{1}=1 \quad \beta_{1}=0.2 \quad \alpha_{2}=1 \quad \beta_{2}=-0.25 \\
& \gamma^{2}=0.001,0.01,0.1 \\
& c=0.2,0.5,0.8 \\
& \phi=0.3,0.6,0.9 .
\end{aligned}
$$

Thus, we consider series with low persistence $(\phi=0.3)$, medium persistence $(\phi=0.6)$ and high persistence $(\phi=0.9)$, and transitions towards the start of the sample $(c=0.2)$, the middle of the sample $(c=0.5)$ and the end of the sample $(c=0.8)$, and allow for slow transitions $\left(\gamma^{2}=0.001\right)$, medium speed transitions $\left(\gamma^{2}=0.01\right)$ and fast transitions $\left(\gamma^{2}=0.1\right)$. Since $\beta_{1}+\beta_{2}<0$, in the long-run there is a negative trend in all the simulated series. In each case 1,000 replications were used.

For each of the 1,000 simulated series the tests $\tau_{\tau}$ and $e_{\alpha \beta}$ were calculated. We then calculated the empirical power of the tests at the $10 \%$ and $5 \%$ nominal sizes. The results are given in Table III and illustrate that for slow transitions $\left(\gamma^{2}=0.001\right)$ the DF test has very little power against the unit root null. Except for the case of an early transition $(c=0.2)$ the null hypothesis is almost never rejected by $\tau_{\tau}$. Conversely, the 
$e_{\alpha \beta}$ test has very good power, often rejecting for over $90 \%$ of the 1,000 simulated series, except for $\phi=0.9$. For the case of fast transitions $\left(\gamma^{2}=0.1\right) \tau_{\tau}$ has more power, particularly when the transition occurs early on in the sample $(c=0.2)$. This is not surprising, since when the transition is early and fast, a large part of the sample resembles a stationary process around a linear trend. When the transition occurs towards the end of the sample however, the power of $\tau_{\tau}$ collapses to zero, whilst the power of $e_{\alpha \beta}$ remains very high, except for $\phi=0.9$.

Clearly, like the DF test at this sample size, the power of $e_{\alpha \beta}$ is low when the degree of persistence is high. For example, for the parameter combination $\gamma^{2}=0.01$, $c=0.5, \phi=0.9$, the $e_{\alpha \beta}$ test rejects the null of a unit root for only 147 of the 1,000 simulated series at the $10 \%$ level of significance. So even though a rejection may fail to be obtained by $e_{\alpha \beta}$ and $\tau_{\tau}$, one should still be cautious of concluding in favour of the unit root hypothesis without further analysis. This experiment does however illustrate the value of allowing for an exponential smooth transition in the deterministic trend function of real exchange rates, since the results show that if a gradual deterministic rise and fall in the series occurs, the DF test will almost always fail to reject the null of a unit root unless this type of structural change is early on in the sample. ${ }^{4}$

\footnotetext{
${ }^{4}$ These results are generally representative of the power of $e_{\alpha \beta}$ for other transition magnitudes. While for this sample size the power of $e_{\alpha \beta}$ is good for series with low and moderate persistence, for series with high persistence ( $\phi=0.9$ ) the test has much less power. Note however that for larger sample sizes $(200,300)$ the power of $e_{\alpha \beta}$ quickly becomes reasonable for series with high persistence. Interestingly, the power of the DF test actually improves for large, very fast transitions, and in some cases overtakes the power of $e_{\alpha \beta}$. When the transition is large and fast, the deterministic rise and fall in the series dominates and the deterministic fall itself resembles a large mean-reversion. Such transition magnitudes are however unlikely to be found in economic time series.
} 
The next experiment investigates the potential loss in power when trend-breaks are gradual but are assumed to be instantaneous. Specifically, empirical powers of the instantaneous three-break test proposed by Papell (2002) (which we will refer to as $t_{b}$ ), are computed when the DGP is in fact a stationary process around a slow exponential smooth transition with long-run PPP imposed. The DGP given by (15) - (18) was used with all combinations of the following parameter values to generate series of 100 observations in length;

$$
\begin{aligned}
& \alpha_{1}=1 \quad \beta_{1}=0.25 \quad \alpha_{2}=1 \quad \beta_{2}=-0.25 \\
& \gamma^{2}=0.001 \\
& c=0.2,0.5,0.8 \\
& \phi=0.3,0.6,0.9 .
\end{aligned}
$$

The DGPs employed here are very similar to those used in the first set of power experiments, however, in this set of experiments the process is restricted to have the same, constant mean before and after the transition $\left(\beta_{1}+\beta_{2}=0\right)$ so as to be consistent with the notion of long-run PPP. The test proposed by Papell (2002) involves estimating the following model;

$$
\begin{aligned}
& y_{t}=\alpha_{1}+\beta_{1} t_{1}+\beta_{2} t_{2}+\beta_{3} t_{3}+v_{t} \\
& \Delta v_{t}=\phi v_{t-1}+\eta_{t}
\end{aligned}
$$


where $t_{i}=t-T B_{i}$ if $t>T B_{i}$ and 0 otherwise, $i=1,2,3$; and testing for a unit root in the fitted residuals $\hat{v}_{t} \cdot{ }^{5}$ Note that in order to impose long-run PPP the following linear restrictions are enforced when estimating the model;

$$
\begin{aligned}
& \beta_{1}+\beta_{2}+\beta_{3}=0 \\
& \beta_{1}\left(T B_{3}-T B_{1}\right)+\beta_{2}\left(T B_{3}-T B_{2}\right)=0
\end{aligned}
$$

The results are given in Table IV.

When the transition occurs early on in the sample $(\tau=0.2), t_{b}$ performs moderately well when persistence is low. For example when $\phi=0.3, \tau=0.2$, the rejection rate at the $10 \%$ level of significance is over $80 \%$. However for all other parameter combinations $t_{b}$ has very low power. This pattern of results is observed since with the transition being so gradual the instantaneous-break model is highly misspecified. The test has some power for the case of an early break since when the transition is early, there is a large part of the sample that resembles a linear trendstationary process; hence rejections of the unit root hypothesis are obtained.

The final experiment compares the power of the instantaneous break test proposed by Papell (2002), with the power of $e_{\alpha}$ when the DGP is a stationary process around a deterministic trend containing three instantaneous breaks with long-run PPP

\footnotetext{
${ }^{5}$ The optimal method for estimating multiple break-points is to globally minimize the residual sum of squares over all possible break-points for the maximum number of breaks considered. Since estimating three break-points in this way is not feasible when conducting power experiments because of the high computational cost, here, an alternative technique is used to estimate the break-points - also used by Papell (2002) when simulating critical values. This involves first estimating a model that allows for a single break; choosing the single break-point by minimizing the residual sum of squares over all possible break-points. Then, imposing this first estimated break-point, the model is re-estimated allowing for a second break-point, chosen in the same way. This is done a third time before testing for a unit root in the residuals from the fitted three-break model.
} 
imposed. The following three-break model is employed as a DGP to generate series of 100 observations in length;

$$
\begin{aligned}
& y_{t}=\alpha_{1}+\beta_{1} t_{1}+\beta_{2} t_{2}+\beta_{3} t_{3}+v_{t} \\
& v_{t}=\phi v_{t-1}+\eta_{t} \\
& \eta_{t} \sim N I D(0,1)
\end{aligned}
$$

where $t_{i}=t-T B_{i}$ if $t>T B_{i}$ and 0 otherwise, $i=1,2,3$. Simulations were carried out for the parameter values $\alpha_{1}=1, \beta_{1}=0.3, \beta_{2}=-0.6, \beta_{3}=0.3, \phi=0.3,0.6,0.9$, and assuming $T B_{1}=24, T B_{2}=49, T B_{3}=74$. Note that in this DGP so as to be consistent with long-run PPP the same constant mean is imposed prior to the first break and after the third break, and hence the comparable ESTR test statistic is $e_{\alpha}$. The results for this final simulation experiment (using the simulated critical values given in Papell, 2002), are given in Table $\mathrm{V}$ and reveal that $t_{b}$ has good power for $\phi=0.3$, although noticeably lower power than $e_{\alpha}$ for $\phi=0.6$. For $\phi=0.9$, the power of both tests declines dramatically at this sample size. ${ }^{6}$ While we limit our analysis in this experiment to $e_{\alpha}$, this pattern of results is similar for the more general ESTR (SESTR) tests at this sample size when the break is instantaneous. The ESTR (SESTR) tests appear to have virtually the same power as $t_{b}$ when persistence is low, but more power than $t_{b}$ for processes of moderate persistence. Both types of test have lower power when persistence is high.

\footnotetext{
${ }^{6}$ Note that both tests have more reasonable power at this degree of persistence for larger sample sizes.
} 
It appears therefore that the instantaneous-break test $t_{b}$ can suffer from a significant loss in power when trend-breaks are gradual, yet conversely the STR based tests appear to perform as well as, if not better than $t_{b}$ when breaks are instantaneous. Note that depending on the exact method used to estimate break-points, in empirical applications $t_{b}$ may well have more power than we find in this experiment. In the power experiments above, for the instantaneous-break model the optimal method of choosing break-points would be to minimize the residual sum of squares over all possible breakpoints for the maximum number of breaks considered. This approach is not feasible in simulation experiments due to the computational cost involved and here an alternative technique is used (see footnote 5).

\section{EMPIRICAL RESULTS FOR U.S. DOLLAR REAL EXCHANGE RATES}

For the empirical analysis in this paper the data consists of quarterly real exchange rates for twenty countries against the U.S. dollar, starting in the first quarter of 1973 and ending in the fourth quarter of $1998 .^{7}$ The natural logarithm of the real exchange rate is used, calculated as

$$
y_{t}=e_{t}+p_{t}^{*}-p_{t}
$$

where $e_{t}$ is the natural logarithm of the nominal dollar exchange rate, $p_{t}^{*}$ is the natural logarithm of the U.S. consumer price index, and $p_{t}$ is the natural logarithm of the

\footnotetext{
${ }^{7}$ We consider the same countries as Papell (2002).
} 
domestic consumer price index. All the data is taken from the IMF International Financial Statistics data set. We compute tests for a shorter sample 1973:1 - 1996:4 investigated by Papell (2002), as well as for the full sample period. To test for purchasing power parity against the unit root hypothesis one has to restrict the pre- and post-break mean of the series under the alternative hypothesis to be the same constant value. This is a feature of the $e_{\alpha}$ and $a e_{\alpha}$ tests. The $e_{\alpha(\beta)}, a e_{\alpha(\beta)}, e_{\alpha \beta}$ and $a e_{\alpha \beta}$ tests do not possess this property. However they have more power against the unit root hypothesis because of their additional generality. Consequently, in this paper we present results for both the $e_{\alpha}, a e_{\alpha}$, and $e_{\alpha \beta}, a e_{\alpha \beta}$ tests. Whilst we experimented with and obtained rejections of the unit root null from the $e_{\alpha(\beta)}$ and $a e_{\alpha(\beta)}$ tests, no additional rejections were obtained compared to the more general $e_{\alpha \beta}$ and $a e_{\alpha \beta}$ tests, and thus for brevity we omit the results of these tests. For all countries the ESTR (SESTR) models were estimated by NLS employing the Broyden, Fletcher, Goldfarb and Shanno (BFGS) numerical optimisation algorithm.

The calculated values of the tests applied to the shorter sample 1973:1 - 1996:4 are given in Table VI. Note that for this data set conventional ADF tests yield no rejections of the unit root hypothesis. The application of $e_{\alpha}$ however leads to a rejection of the unit root hypothesis for four of the twenty countries. Since $e_{\alpha}$ imposes the same pre- and post-transition mean on the series, the alternative hypothesis in this case is consistent with long-run PPP. When the more general test $e_{\alpha \beta}$ is applied, the number of rejections of the unit root hypothesis increases to eleven. Seven of the eleven rejections obtained from $e_{\alpha \beta}$ are at the $5 \%$ level of significance, and for France the null hypothesis of a unit root is rejected at the $1 \%$ level of significance. 
In Figures 2(a) - 2(k) the real exchange rates series and fitted trend functions are graphed for the countries for which a rejection of the unit root null is obtained from $e_{\alpha \beta}$. There is an obvious linking factor for these countries: they all experience a rise and fall in their real exchange rate centred around 1984 (as a result of the dramatic nominal appreciation and depreciation of the dollar). Comparing these graphs with the dates for the trend-breaks estimated by Papell (2002) reveals that here, we estimate very similar break dates for the largest visible change in the trend function. The large rise in the trend in real exchange rates starts around the beginning of 1980, the turning point occurs in the mid-1980s, and the final transition occurs in the late-1980s. Interestingly, another common pattern in many of these series is a fall in the mid- to late-1970s, prior to the large appreciation of the dollar in the 1980s. This is picked up by an initial decline in the trend function of the ESTR model before the large rise, and can be attributed to the nominal depreciation of the dollar as a result of the shift from fixed to flexible exchange rate systems in the early 1970 s and the rise in U.S. inflation relative to these countries over the period 1977-1979. It appears that for many of the countries in our sample, in a sense, we identify four breaks (or five regimes).

When the $a e_{\alpha}$ and $a e_{\alpha \beta}$ tests are applied, surprisingly perhaps given their increased generality, the evidence against the unit root hypothesis is weaker. Only a single rejection is now obtained from $a e_{\alpha}$ (consistent with long-run PPP under the alternative hypothesis) and only nine rejections are obtained from the more general $a e_{\alpha \beta}$ test. From a visual analysis of graphs of the fitted transitions, see Figures 3(a) and 3(b) for France and Norway as examples, it is clear that the asymmetric models fit the data noticeably better than the symmetric alternatives. However the smaller number of 
rejections from $a e_{\alpha}$ and $a e_{\alpha \beta}$ should not in all cases be taken as evidence that the additional rejections from the symmetric tests reported in Table VI are due to a misspecified (symmetric) model being used, since there is a trade-off between flexibility of the model under the alternative hypothesis and power of the test. A consequence of the better fitting asymmetric exponential transition function is that the variance of the data around the deterministic trend is reduced, and consequently for samples of this size, ceteris parabus, the asymmetric tests tend to have less power than the symmetric versions. Furthermore, if a series is in fact stationary around a symmetric transition, but the asymmetric tests are used, the estimation of an additional irrelevant parameter means that the power of the asymmetric tests against the unit root null will be lower than that of the symmetric tests.

The calculated test statistics for the longer sample period 1973:1 - 1998:4 are given in Table VII. As can been seen from the graphs Figure 2(a) - 2(k) (which are for the sample period 1973:1 - 1996:4), a number of the series for which rejections of the unit root hypothesis are obtained by $e_{\alpha \beta}$, but are not obtained by $e_{\alpha}$ (and therefore long-run PPP is not supported), contain a negatively sloped deterministic trend in the last part of the sample. Note however that the dollar appreciated against many of the countries in our sample between 1996:4 and 1998:4, and therefore including this period may increase the support for long-run PPP.

We find that the overall pattern of rejections from these tests for the longer sample period remains similar to the results for the shorter sample. The largest number of rejections (ten) is obtained from $e_{\alpha \beta}$, with fewer rejections obtained from the tests that impose long-run PPP (five from $e_{\alpha}$, and one from $a e_{\alpha}$ ). For many of the countries 
the contrasting evidence from $e_{\alpha}, a e_{\alpha}$, and $e_{\alpha \beta}, a e_{\alpha \beta}$ is undoubtedly due to the presence of negatively sloped deterministic trends in the pre-appreciation and postdepreciation periods (particularly when the shorter sample is used), indicating that the dollar experienced a long-run real depreciation over this period, albeit interrupted by the structural change of the 1980s (this is confirmed by the estimated parameter values for the models used to derive $e_{\alpha \beta}$ and $a e_{\alpha \beta}$, which for brevity are omitted). The models used to derive $e_{\alpha}$ and $a e_{\alpha}$ are unable to capture these trends and therefore fewer rejections of the unit root hypothesis are found.

It is important to stress that $e_{\alpha \beta}$ and $a e_{\alpha \beta}$ are not tests for long-run PPP. The rejections obtained from $e_{\alpha \beta}$ and $a e_{\alpha \beta}$ simply reveal that the hypothesis of stationarity around a non-linear trend is preferred to the hypothesis of a unit root. As discussed in Papell (2002), for a trend-break model to be consistent with long-run PPP, one would have to assume that the trend-breaks are determined by exogenous events, and restrict the pre-break and post-break means to be equal to the same constant value. This latter restriction is implicitly made when the $e_{\alpha}$ and $a e_{\alpha}$ tests are used, however, it is also possible to impose long-run PPP within a more general model. Consider the following ESTR model for one of the series for which a rejection of the unit root hypothesis has been obtained from $e_{\alpha \beta}$;

$$
\begin{aligned}
& y_{t}=\alpha_{1}+\alpha_{2} E_{t}(\gamma, c)+\beta_{1} t\left(1-E_{t}(\gamma, c)\right)+v_{t} \\
& E_{t}(\gamma, c)=\left(1-\exp \left\{-\gamma^{2}[t-c T]^{2}\right\}\right),
\end{aligned}
$$

where $v_{t}$ is a zero-mean $\mathrm{I}(0)$ process; 


$$
v_{t}=\sum_{i=1}^{k+1} \phi_{i} v_{t-i}+\eta_{t}
$$

In the long-run (that is, when $(t-c T) \rightarrow \pm \infty)$ the intercept in (24) is $\alpha_{1}+\alpha_{2}$ and the trend is zero. Therefore this model is consistent with long-run PPP. It can also be written as

$$
\begin{aligned}
& y_{t}=\alpha_{1}+\beta_{1} t+\alpha_{2} E_{t}(\gamma, c)+\beta_{2} t E_{t}(\gamma, c)+v_{t} \\
& E_{t}(\gamma, c)=\left(1-\exp \left\{-\gamma^{2}[t-c T]^{2}\right\}\right) \\
& v_{t}=\sum_{i=1}^{k+1} \phi_{i} v_{t-i}+\eta_{t},
\end{aligned}
$$

subject to the restriction $\beta_{1}+\beta_{2}=0$, and an asymmetric version can be obtained by replacing $E_{t}(\gamma, c)$ with $S E_{t}\left(\gamma_{1}, \gamma_{2}, c\right)$. Thus, having obtained rejections from $e_{\alpha \beta}$ and/or $a e_{\alpha \beta}$, to test for long-run PPP one simply needs to test the linear restriction $\beta_{1}+\beta_{2}=0$ in (27) - (29), and/or the asymmetric version of this model.

Given that $e_{\alpha}$ and $a e_{\alpha}$ already provide tests of the unit root hypothesis that allow for gradual breaks but impose long-run PPP under the alternative hypothesis - is there any advantage to be gained by using these additional tests? The answer to this question involves a point already mentioned: prior to the large nominal appreciation of the dollar in the 1980s, towards the end of the 1970s the dollar depreciated against the currencies of a number of the countries in this sample, with pass-through to their real exchange rates. The models used to calculate $e_{\alpha}$ and $a e_{\alpha}$ are unable to capture this 
initial depreciation in addition to the structural change of the 1980s. However, due to the increased flexibility of the trend function in (27) (and (27) with $E_{t}(\gamma, c)$ replaced by $\left.S E_{t}\left(\gamma_{1}, \gamma_{2}, c\right)\right)$, these more general models are able to capture this initial depreciation, in addition to the structural change of the 1980 s, while still maintaining long-run PPP if appropriate parameter restrictions are imposed.

We tested the restriction $\beta_{1}+\beta_{2}=0$ using the model (27) - (29) (ESTR) and an asymmetric (SESTR) version of this model for the series for which rejections were obtained from $e_{\alpha \beta}$ and $a e_{\alpha \beta}$. For each series and model a likelihood ratio (LR) statistic for testing the restriction $\beta_{1}+\beta_{2}=0$ is reported in Table VIII for both the shorter sample 1973:1 - 1996:4 and the full sample 1973:1 - 1998:4. ${ }^{8}$ For the shorter sample, and the ESTR model the only country for which the linear restriction $\beta_{1}+\beta_{2}=0$ cannot be rejected at the 5\% significance level is Norway. For the shorter sample and the SESTR model this restriction is not rejected for Norway and Italy. For the full sample the ESTR model fails to reject the restriction $\beta_{1}+\beta_{2}=0$ at the $5 \%$ significance level for Belgium, Denmark, France, Germany, Italy and the Netherlands. Thus, for the full sample of data, evidence supporting PPP is found for three countries (Italy, the Netherlands and Belgium) from these LR tests which is not found when $e_{\alpha}$ is used. For the full sample and the SESTR model, the restriction $\beta_{1}+\beta_{2}=0$ cannot be rejected for Belgium, France and Italy. There is no support for long-run PPP from $a e_{\alpha}$ for these countries. Note that in some cases (e.g. Greece, Portugal) we find support for long-run

\footnotetext{
${ }^{8}$ Since the unit root hypothesis has been rejected, these LR statistics for testing $\beta_{1}+\beta_{2}=0$ are assumed to have a $\chi^{2}$ distribution with 1 degree of freedom.
} 
PPP from $e_{\alpha}$ and $a e_{\alpha}$ but find no support from the LR test. The application of both of these different forms of test for long-run PPP is therefore warranted.

\section{CONCLUSION}

This paper has focused on deterministic trend-breaks in quarterly real exchange rates for twenty countries against the U.S. dollar. Tests of the null hypothesis of a unit root are developed that allow under the alternative hypothesis for an endogenously determined non-monotonic smooth transition in the trend function of the DGP. Critical values for the tests are obtained by Monte Carlo simulation methods, and the empirical size and power of the tests is investigated through a number of simulation experiments. Conventional univariate Dickey-Fuller-type tests reveal virtually no evidence against the null of a unit root for the countries in this sample, and recently developed instantaneous trend-break unit root tests also reveal no evidence against the unit root hypothesis. In contrast, the univariate tests proposed in this paper, which allow for a gradually changing trend function, find that the unit root hypothesis can be rejected for many of the countries examined.

Papell (2002) argues that the nominal behaviour of the dollar in the 1980s should be modelled as breaks in a deterministic trend in dollar-based real exchange rates. Whilst Papell finds that univariate models allowing for instantaneous trend-breaks do not support long-run PPP, he develops panel data unit root tests allowing for instantaneous trend-breaks that do reveal evidence against the unit root hypothesis. We find that the real exchange rates for a number of the countries analysed by Papell (2002) are very well approximated as smooth transition trend-stationary processes, dominated 
by a deterministic rise and fall coinciding with the dramatic nominal appreciation and depreciation of the dollar in the 1980s. This does not mean that the hypothesis of longrun PPP is supported for all these countries, as for many, a negative deterministic trend is found in the pre-appreciation and post-depreciation periods, picking up a long-run real depreciation of the dollar against these currencies. For a small number of countries including France, Germany and Italy, our evidence suggests that long-run PPP has existed with the U.S., but that such evidence is obscured by the appreciation and depreciation of the dollar in the 1980s. 


\section{REFERENCES}

Anderson HM. 1997. Transaction costs and non-linear adjustment towards equilibrium in the US Treasury bill market. Oxford Bulletin of Economics and Statistics 59: 465484.

Bai J. 1999. Likelihood ratio tests for multiple structural changes. Journal of Econometrics 91: 299-323.

Dickey DA, Fuller WA. 1979. Distribution of the estimators for autoregressive time series with a unit root. Journal of the American Statistical Association 74: 427-431.

Granger CWJ, Teräsvirta T. 1993. Modelling Non-linear Economic Relationships. Oxford: Oxford University Press.

Harvey DI, Mills TC. 2002. Unit Roots and double smooth transitions. Journal of Applied Statistics 29: 675-683.

Leybourne SJ, Newbold P, Vougas D. 1998. Unit roots and smooth transitions. Journal of Time Series Analysis 19: 83-97.

Lin C-FJ, Teräsvirta T. 1994. Testing the constancy of regression parameters against continuous structural change. Journal of Econometrics 62: 211-228. 
Michael P, Nobay AR, Peel DA. 1997. Transactions costs and non-linear adjustment in real exchange rates: an empirical investigation. Journal of Political Economy 105: 862879.

Mizen P, Leybourne SJ. 1999. Understanding the disinflation in Australia, Canada and New Zealand using evidence from smooth transition analysis. Journal of International Money and Finance 18: 799-816.

Papell DH. 1997. Searching for stationarity: purchasing power parity under the current float. Journal of International Economics 43: 313-332.

Papell DH. 2002. The great appreciation, the great depreciation, and the purchasing power parity hypothesis. Journal of International Economics 57: 51-82.

Rothman P, van Dijk D, Franses PH. 1999. A multivariate STAR analysis of the relationship between money and output. Econometric Institute Report 9945/A, Erasmus University Rotterdam.

Sollis R, Leybourne SJ, Newbold P. 2002. Tests for symmetric and asymmetric nonlinear mean reversion in real exchange rates. Journal of Money, Credit and Banking 34: 686-700

Swanson NR. 1999. Finite sample properties of a simple LM test for neglected nonlinearity in error-correcting regression equations. Statistica Neerlandica 53: 76-95. 
Taylor MP, Peel DA, Sarno L. 2001. Non-linear mean-reversion in real exchange rates: towards a solution to the purchasing power parity puzzles. International Economic Review 42: 1015-1042.

Teräsvirta T. 1994. Specification, estimation and evaluation of smooth transition autoregressive models. Journal of the American Statistical Association 89: 208-218.

Teräsvirta T, Anderson HM. 1992. Characterising non-linearities in business cycles using smooth transition autoregressive models. Journal of Applied Econometrics 7: 119136.

Teräsvirta T, Tjøstheim D, Granger CWJ. 1994. Aspects of modelling non-linear time series. In Handbook of Econometrics, vol. IV, Engle RF, McFadden DL, (eds). Elsevier Science: Amsterdam.

van Dijk D, Franses PH. 1999. Modelling multiple regimes in the business cycle. Macroeconomic Dynamics 3: 311-340.

van Dijk D, Franses PH. 2000. Non-linear error-correction models for interest rates in the Netherlands. In Non-linear Econometric Modelling in Time Series Analysis, Barnett WA, Hendry DF, Hyelleberg S, Teräsvirta T, Tjøstheim D., Wurtz AH. (eds). Cambridge University Press: Cambridge. 
Wu Y. 1996. Are real exchange rates nonstationary? Evidence from a panel data test. Journal of Money, Credit and Banking 28: 54-63. 
Table I. Null critical values for unit root tests against stationarity around symmetric and asymmetric exponential smooth transitions

\begin{tabular}{cccccccccc}
\hline \multicolumn{8}{c}{ Null critical values at $0.10,0.05$ and 0.01 nominal sizes. } \\
\hline \multicolumn{1}{c}{$e_{\alpha}$} & \multicolumn{7}{c}{$e_{\alpha(\beta)}$} \\
& 0.10 & 0.05 & 0.01 & 0.10 & 0.05 & 0.01 & 0.10 & 0.05 & 0.01 \\
\hline 100 & -3.946 & -4.288 & -4.949 & -4.404 & -4.760 & -5.453 & -4.761 & -5.057 & -5.711 \\
200 & -3.856 & -4.194 & -4.846 & -4.328 & -4.628 & -5.226 & -4.627 & -4.958 & -5.517 \\
500 & -3.823 & -4.123 & -4.732 & -4.244 & -4.544 & -5.130 & -4.569 & -4.881 & -5.414 \\
& & $a e_{\alpha}$ & & & $a e_{\alpha(\beta)}$ & & & $a e_{\alpha \beta}$ & \\
100 & -4.179 & -4.550 & -5.200 & -4.660 & -4.990 & -5.648 & -4.877 & -5.200 & -5.979 \\
200 & -4.095 & -4.395 & -4.929 & -4.547 & -4.893 & -5.442 & -4.751 & -5.063 & -5.748 \\
500 & -3.977 & -4.316 & -4.876 & -4.449 & -4.730 & -5.318 & -5.036 & -5.036 & -5.644 \\
\hline
\end{tabular}


Table II. Empirical sizes of $e_{\alpha}$ for $\operatorname{ARIMA}(1,1,0)$ processes with $k$ lags in step-two of the testing procedure

\begin{tabular}{cccccccc}
\hline \multicolumn{7}{c}{ Empirical size of $e_{\alpha}$ at $0.10,0.05$ and 0.01 nominal sizes. } \\
\hline$\phi$ & $k$ & \multicolumn{5}{c}{$T=100$} & \\
& & 0.10 & 0.05 & 0.01 & 0.10 & 0.05 & 0.01 \\
\hline 0 & 0 & 0.098 & 0.052 & 0.010 & 0.105 & 0.053 & 0.012 \\
0 & 1 & 0.102 & 0.046 & 0.005 & 0.111 & 0.047 & 0.007 \\
0 & 4 & 0.080 & 0.036 & 0.006 & 0.100 & 0.042 & 0.009 \\
-0.4 & 0 & 0.438 & 0.305 & 0.149 & 0.715 & 0.598 & 0.351 \\
-0.4 & 1 & 0.082 & 0.032 & 0.002 & 0.107 & 0.061 & 0.012 \\
-0.4 & 4 & 0.081 & 0.040 & 0.006 & 0.168 & 0.076 & 0.015 \\
0.4 & 0 & 0.006 & 0.003 & 0.001 & 0.008 & 0.000 & 0.000 \\
0.4 & 1 & 0.085 & 0.032 & 0.008 & 0.107 & 0.061 & 0.010 \\
0.4 & 4 & 0.081 & 0.030 & 0.004 & 0.136 & 0.059 & 0.012 \\
\hline
\end{tabular}


Table III. Empirical powers of $e_{\alpha \beta}$, and $\tau_{\tau}$ for a stationary AR(1) generating process around an exponential smooth transition

\begin{tabular}{|c|c|c|c|c|c|c|}
\hline \multicolumn{7}{|c|}{ Empirical powers at 0.10 and 0.05 nominal sizes. } \\
\hline \multirow[t]{2}{*}{$\gamma^{2}$} & \multirow[t]{2}{*}{$c$} & \multirow[t]{2}{*}{$\phi$} & \multicolumn{2}{|c|}{$e_{\alpha \beta}$} & \multicolumn{2}{|c|}{$\tau_{\tau}$} \\
\hline & & & 0.10 & 0.05 & 0.10 & 0.05 \\
\hline 0.001 & 0.2 & 0.3 & 0.981 & 0.981 & 0.537 & 0.176 \\
\hline 0.001 & 0.5 & 0.3 & 0.946 & 0.941 & 0.000 & 0.000 \\
\hline 0.001 & 0.8 & 0.3 & 0.979 & 0.979 & 0.003 & 0.000 \\
\hline 0.001 & 0.2 & 0.6 & 0.914 & 0.837 & 0.171 & 0.041 \\
\hline 0.001 & 0.5 & 0.6 & 0.870 & 0.783 & 0.000 & 0.000 \\
\hline 0.001 & 0.8 & 0.6 & 0.889 & 0.798 & 0.001 & 0.000 \\
\hline 0.001 & 0.2 & 0.9 & 0.138 & 0.083 & 0.095 & 0.046 \\
\hline 0.001 & 0.5 & 0.9 & 0.172 & 0.084 & 0.000 & 0.000 \\
\hline 0.001 & 0.8 & 0.9 & 0.140 & 0.066 & 0.008 & 0.003 \\
\hline 0.01 & 0.2 & 0.3 & 1.00 & 1.000 & 0.999 & 0.994 \\
\hline 0.01 & 0.5 & 0.3 & 0.979 & 0.979 & 0.000 & 0.000 \\
\hline 0.01 & 0.8 & 0.3 & 0.936 & 0.936 & 0.000 & 0.000 \\
\hline 0.01 & 0.2 & 0.6 & 0.928 & 0.830 & 0.866 & 0.650 \\
\hline 0.01 & 0.5 & 0.6 & 0.922 & 0.824 & 0.000 & 0.000 \\
\hline 0.01 & 0.8 & 0.6 & 0.875 & 0.793 & 0.000 & 0.000 \\
\hline 0.01 & 0.2 & 0.9 & 0.136 & 0.078 & 0.142 & 0.069 \\
\hline 0.01 & 0.5 & 0.9 & 0.147 & 0.082 & 0.000 & 0.000 \\
\hline 0.01 & 0.8 & 0.9 & 0.099 & 0.041 & 0.000 & 0.000 \\
\hline 0.1 & 0.2 & 0.3 & 1.000 & 1.000 & 1.000 & 1.000 \\
\hline 0.1 & 0.5 & 0.3 & 1.000 & 1.000 & 0.242 & 0.018 \\
\hline 0.1 & 0.8 & 0.3 & 1.000 & 1.000 & 0.000 & 0.000 \\
\hline 0.1 & 0.2 & 0.6 & 0.892 & 0.769 & 0.996 & 0.958 \\
\hline 0.1 & 0.5 & 0.6 & 0.879 & 0.735 & 0.020 & 0.000 \\
\hline 0.1 & 0.8 & 0.6 & 0.858 & 0.719 & 0.000 & 0.000 \\
\hline 0.1 & 0.2 & 0.9 & 0.070 & 0.031 & 0.208 & 0.090 \\
\hline 0.1 & 0.5 & 0.9 & 0.040 & 0.016 & 0.007 & 0.000 \\
\hline 0.1 & 0.8 & 0.9 & 0.024 & 0.008 & 0.000 & 0.000 \\
\hline
\end{tabular}


Table IV. Empirical powers of $t_{b}$ for a stationary AR(1) generating process around a slow exponential smooth transition with long-run PPP imposed

\begin{tabular}{ccccc}
\hline \multicolumn{3}{c}{ Empirical powers at 0.10 and 0.05 nominal sizes. } \\
\hline$\gamma^{2}$ & $c$ & $\phi$ & \multicolumn{2}{c}{$t_{b}$} \\
& & & 0.10 & 0.05 \\
\hline 0.001 & 0.2 & 0.3 & 0.839 & 0.558 \\
0.001 & 0.5 & 0.3 & 0.084 & 0.008 \\
0.001 & 0.8 & 0.3 & 0.000 & 0.000 \\
0.001 & 0.2 & 0.6 & 0.327 & 0.142 \\
0.001 & 0.5 & 0.6 & 0.004 & 0.000 \\
0.001 & 0.8 & 0.6 & 0.000 & 0.000 \\
0.001 & 0.2 & 0.9 & 0.057 & 0.017 \\
0.001 & 0.5 & 0.9 & 0.002 & 0.000 \\
0.001 & 0.8 & 0.9 & 0.000 & 0.000 \\
\hline
\end{tabular}


Table V. Empirical powers of $e_{\alpha}$ and $t_{b}$ for a stationary AR(1) generating process around a deterministic trend with three instantaneous breaks and long-run PPP imposed

\begin{tabular}{cccccc}
\hline \multicolumn{6}{c}{ Empirical powers at 0.10 and 0.05 nominal sizes. } \\
\hline$\phi$ & \multicolumn{2}{c}{$e_{\alpha}$} & & $t_{b}$ & \\
& 0.10 & 0.05 & 0.10 & 0.05 \\
\hline 0.3 & 0.995 & 0.995 & 0.993 & 0.967 \\
0.6 & 0.967 & 0.941 & 0.768 & 0.503 \\
0.9 & 0.204 & 0.110 & 0.082 & 0.038 \\
\hline
\end{tabular}


Table VI. Calculated values of ESTR and SESTR tests for real exchange rates $1973: 1-1996: 4$

\begin{tabular}{|c|c|c|c|c|c|c|c|c|}
\hline & $k$ & $e_{\alpha}$ & $k$ & $e_{\alpha \beta}$ & $K$ & $a e_{\alpha}$ & $k$ & $a e_{\alpha \beta}$ \\
\hline Australia & 3 & -3.601 & 3 & -3.029 & 3 & -3.134 & 3 & -3.531 \\
\hline Austria & 0 & -3.680 & 8 & $-5.356^{b}$ & 2 & -2.473 & 4 & $-4.954^{a}$ \\
\hline Belgium & 3 & -3.147 & 4 & $-5.563^{b}$ & 3 & -3.642 & 4 & $-5.574^{b}$ \\
\hline Canada & 6 & -2.274 & 7 & -3.438 & 6 & -2.227 & 7 & -4.359 \\
\hline Denmark & 3 & $-4.077^{a}$ & 8 & $-5.431^{b}$ & 2 & -3.039 & 3 & -4.534 \\
\hline Finland & 5 & -2.752 & 7 & -3.955 & 6 & -2.763 & 7 & -3.933 \\
\hline France & 4 & $-4.542^{b}$ & 4 & $-6.003^{c}$ & 0 & -4.038 & 4 & $-5.231^{b}$ \\
\hline Germany & 4 & $-4.117^{\mathrm{a}}$ & 4 & $-5.209^{b}$ & 2 & -2.807 & 4 & -4.609 \\
\hline Greece & 4 & -3.860 & 4 & $-5.292^{b}$ & 4 & -4.156 & 4 & $-4.906^{\mathrm{a}}$ \\
\hline Ireland & 3 & -2.785 & 8 & -4.334 & 7 & -3.563 & 4 & -4.409 \\
\hline Italy & 0 & -2.740 & 4 & -4.600 & 0 & -2.860 & 4 & $-4.903^{\mathrm{a}}$ \\
\hline Japan & 4 & -3.443 & 4 & $-4.949^{a}$ & 4 & -3.068 & 4 & -4.452 \\
\hline Netherlands & 3 & -3.336 & 4 & $-5.510^{b}$ & 2 & -2.488 & 4 & $-4.884^{a}$ \\
\hline New Zealand & 3 & -3.498 & 3 & -3.651 & 3 & -3.690 & 3 & -3.980 \\
\hline Norway & 0 & $-4.837^{\mathrm{c}}$ & 0 & $-5.000^{a}$ & 0 & $-5.045^{b}$ & 0 & $-5.272^{b}$ \\
\hline Portugal & 0 & -3.844 & 8 & $-4.764^{a}$ & 0 & -3.837 & 8 & $-4.943^{\mathrm{a}}$ \\
\hline Spain & 0 & -2.820 & 8 & -3.125 & 0 & -2.813 & 8 & -3.075 \\
\hline Sweden & 3 & -3.243 & 8 & -4.592 & 3 & -3.392 & 8 & -4.597 \\
\hline Switzerland & 0 & -3.273 & 4 & $-5.528^{b}$ & 0 & -3.347 & 4 & $-4.923^{\mathrm{a}}$ \\
\hline U.K. & 5 & -2.138 & 5 & -2.661 & 5 & -2.137 & 5 & -2.616 \\
\hline
\end{tabular}

Superscripts a, b and c denote significance at the $10 \%, 5 \%$ and $1 \%$ levels respectively. $k$ is the order of autoregressive terms included when carrying out the test. The value of $k$ was determined using the general-to-specific testing strategy, starting with $k=8$ and including all lags up to the last lag with a $t$ statistic significant at the $5 \%$ level. 
Table VII. Calculated values of ESTR and SESTR tests for real exchange rates $1973: 1-1998: 4$

\begin{tabular}{|c|c|c|c|c|c|c|c|c|}
\hline & $k$ & $e_{\alpha}$ & $k$ & $e_{\alpha \beta}$ & $\bar{K}$ & $a e_{\alpha}$ & $k$ & $a e_{\alpha \beta}$ \\
\hline Australia & 3 & -2.973 & 3 & -3.476 & 0 & -3.058 & 3 & -3.053 \\
\hline Austria & 0 & -3.815 & 4 & $-4.967^{a}$ & 2 & -2.714 & 4 & -4.194 \\
\hline Belgium & 3 & -3.045 & 4 & $-5.212^{b}$ & 3 & -2.933 & 4 & $-5.212^{b}$ \\
\hline Canada & 3 & -2.290 & 3 & -3.513 & 3 & -1.975 & 7 & -4.288 \\
\hline Denmark & 3 & $-4.219^{a}$ & 4 & $-4.958^{a}$ & 3 & -3.861 & 3 & -4.095 \\
\hline Finland & 5 & -2.454 & 4 & $-5.056^{\mathrm{a}}$ & 5 & -2.475 & 7 & -4.512 \\
\hline France & 4 & $-4.442^{b}$ & 4 & $-5.443^{b}$ & 4 & -4.117 & 4 & $-5.106^{\mathrm{a}}$ \\
\hline Germany & 4 & $-4.242^{\mathrm{a}}$ & 4 & $-5.172^{\mathrm{a}}$ & 4 & -3.650 & 4 & -4.297 \\
\hline Greece & 4 & $-4.535^{b}$ & 4 & $-5.821^{c}$ & 4 & $-4.828^{b}$ & 4 & $-5.829^{b}$ \\
\hline Ireland & 7 & -3.042 & 6 & -2.266 & 3 & -3.451 & 3 & -4.254 \\
\hline Italy & 0 & -2.829 & 4 & $-4.947^{a}$ & 0 & -2.924 & 4 & $-5.346^{b}$ \\
\hline Japan & 0 & -2.567 & 0 & -2.724 & 0 & -2.639 & 0 & -2.747 \\
\hline Netherlands & 4 & -3.809 & 4 & $-5.415^{b}$ & 2 & -2.353 & 4 & -4.550 \\
\hline New Zealand & 0 & -2.257 & 0 & -3.298 & 0 & -3.536 & 0 & -3.122 \\
\hline Norway & 7 & -2.243 & 7 & -3.071 & 2 & -2.530 & 7 & -3.595 \\
\hline Portugal & 3 & $-4.040^{a}$ & 8 & -4.514 & 3 & -4.007 & 8 & $-5.468^{b}$ \\
\hline Spain & 0 & -2.821 & 0 & -2.690 & 0 & -2.815 & 3 & -3.820 \\
\hline Sweden & 3 & -2.333 & 8 & -3.815 & 3 & -2.400 & 8 & $-4.892^{\mathrm{a}}$ \\
\hline Switzerland & 4 & -3.705 & 4 & $-4.974^{a}$ & 0 & -3.515 & 4 & -4.285 \\
\hline U.K. & 5 & -2.234 & 5 & -2.774 & 5 & -2.234 & 5 & -2.731 \\
\hline
\end{tabular}

Superscripts a, b and $\mathrm{c}$ denote significance at the $10 \%, 5 \%$ and $1 \%$ levels respectively. $k$ is the order of autoregressive terms included when carrying out the test. The value of $k$ was determined using the general-to-specific testing strategy, starting with $k=8$ and including all lags up to the last lag with a $t$ statistic significant at the $5 \%$ level. 
Table VIII. Likelihood ratio tests of long-run PPP using general ESTR and SESTR models

\begin{tabular}{lcccc}
\hline & \multicolumn{2}{c}{$1973: 1-1996: 4$} & \multicolumn{2}{c}{$1973: 1-1998: 4$} \\
\hline Austria & ESTR & SESTR & ESTR & SESTR \\
Belgium & $\mathbf{6 4 . 5 4 9}$ & $\mathbf{6 8 . 6 9 8}$ & $\mathbf{3 . 9 0 6}$ & NA \\
Denmark & $\mathbf{1 1 . 5 0 0}$ & $\mathbf{4 7 . 1 9 1}$ & 0.226 & 0.296 \\
Finland & $\mathbf{2 2 . 0 4 9}$ & NA & 0.016 & NA \\
France & NA & NA & $\mathbf{1 1 . 2 0 8}$ & $\mathbf{1 3 . 3 7 7}$ \\
Germany & $\mathbf{1 1 . 0 3 6}$ & $\mathbf{3 6 . 0 5 7}$ & 0.238 & 3.228 \\
Greece & $\mathbf{1 4 . 8 4 1}$ & NA & 1.525 & NA \\
Italy & $\mathbf{2 6 . 6 2 8}$ & $\mathbf{8 9 . 4 2 2}$ & $\mathbf{2 1 . 0 2 9}$ & $\mathbf{1 7 . 5 2 6}$ \\
Japan & NA & 2.459 & 1.180 & 0.630 \\
Netherlands & $\mathbf{7 9 . 2 8 9}$ & NA & NA & NA \\
Norway & $\mathbf{1 1 . 2 5 7}$ & $\mathbf{3 4 . 1 1 5}$ & 0.499 & NA \\
Portugal & .024 & 2.510 & NA & NA \\
Sweden & $\mathbf{2 5 . 6 2 9}$ & $\mathbf{3 0 . 8 1 0}$ & NA & $\mathbf{3 9 . 9 5 4}$ \\
Switzerland & NA & NA & NA & $\mathbf{1 3 . 9 0 1}$ \\
\hline
\end{tabular}

Rejections at the 5\% significance level are in bold. 


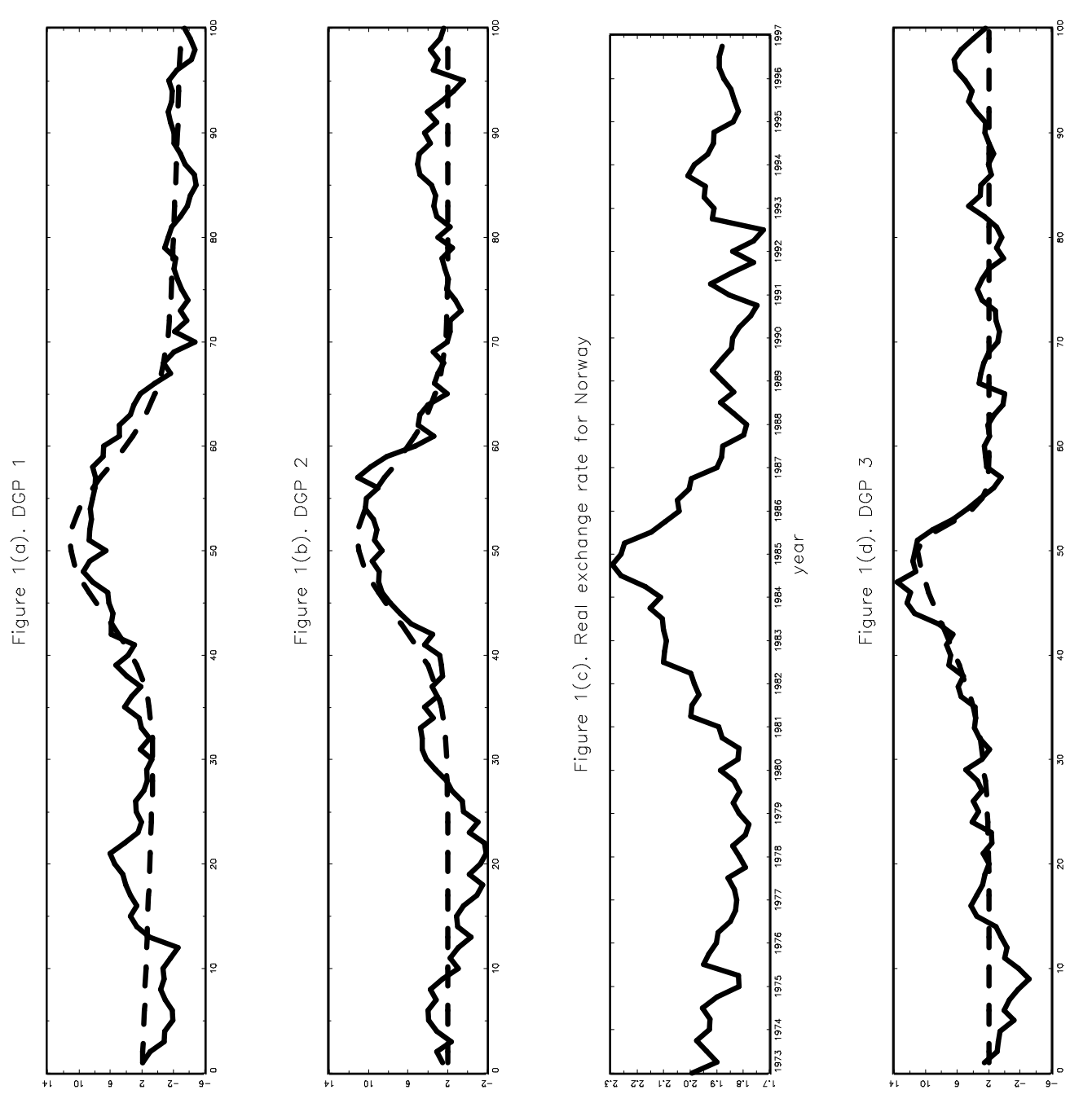



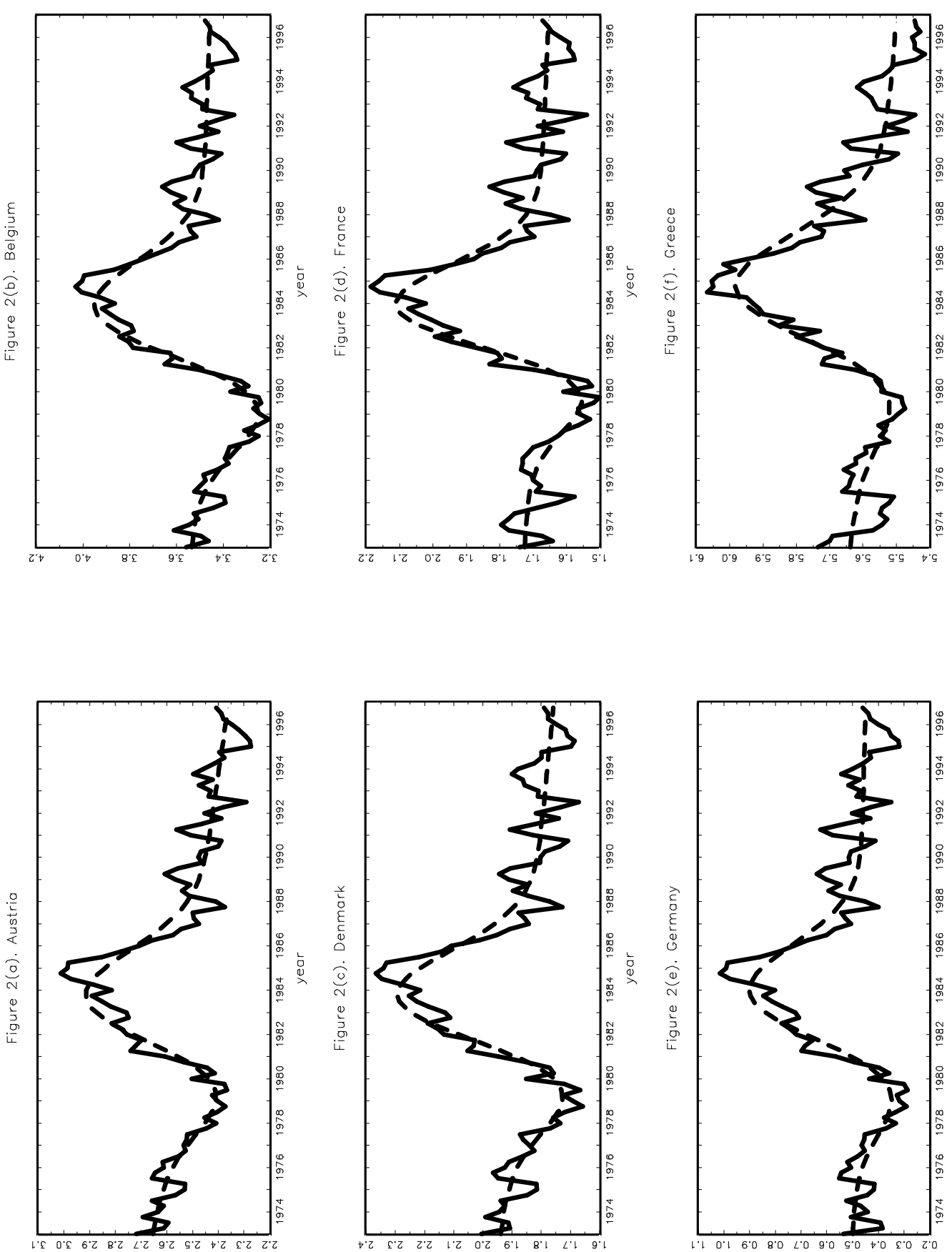

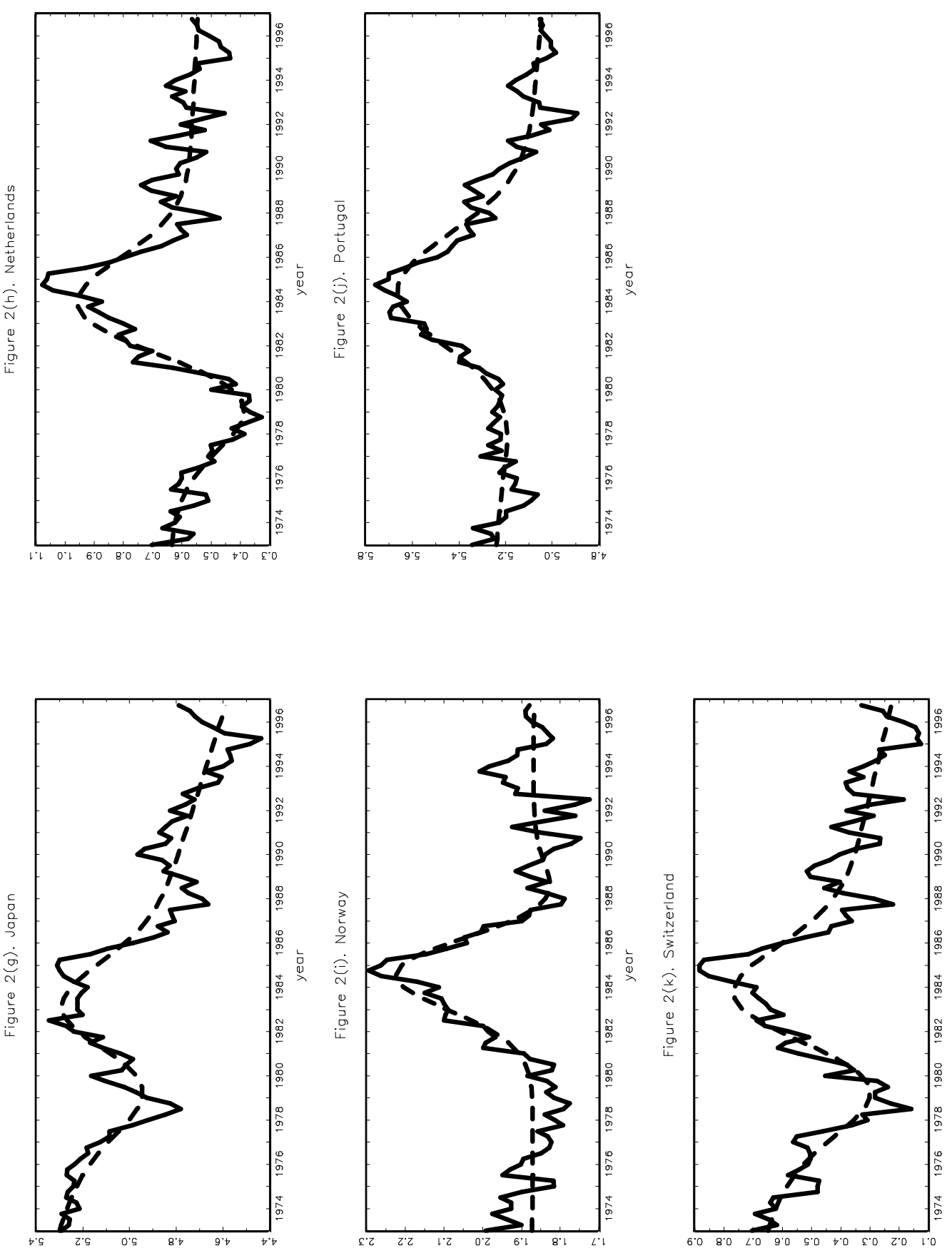

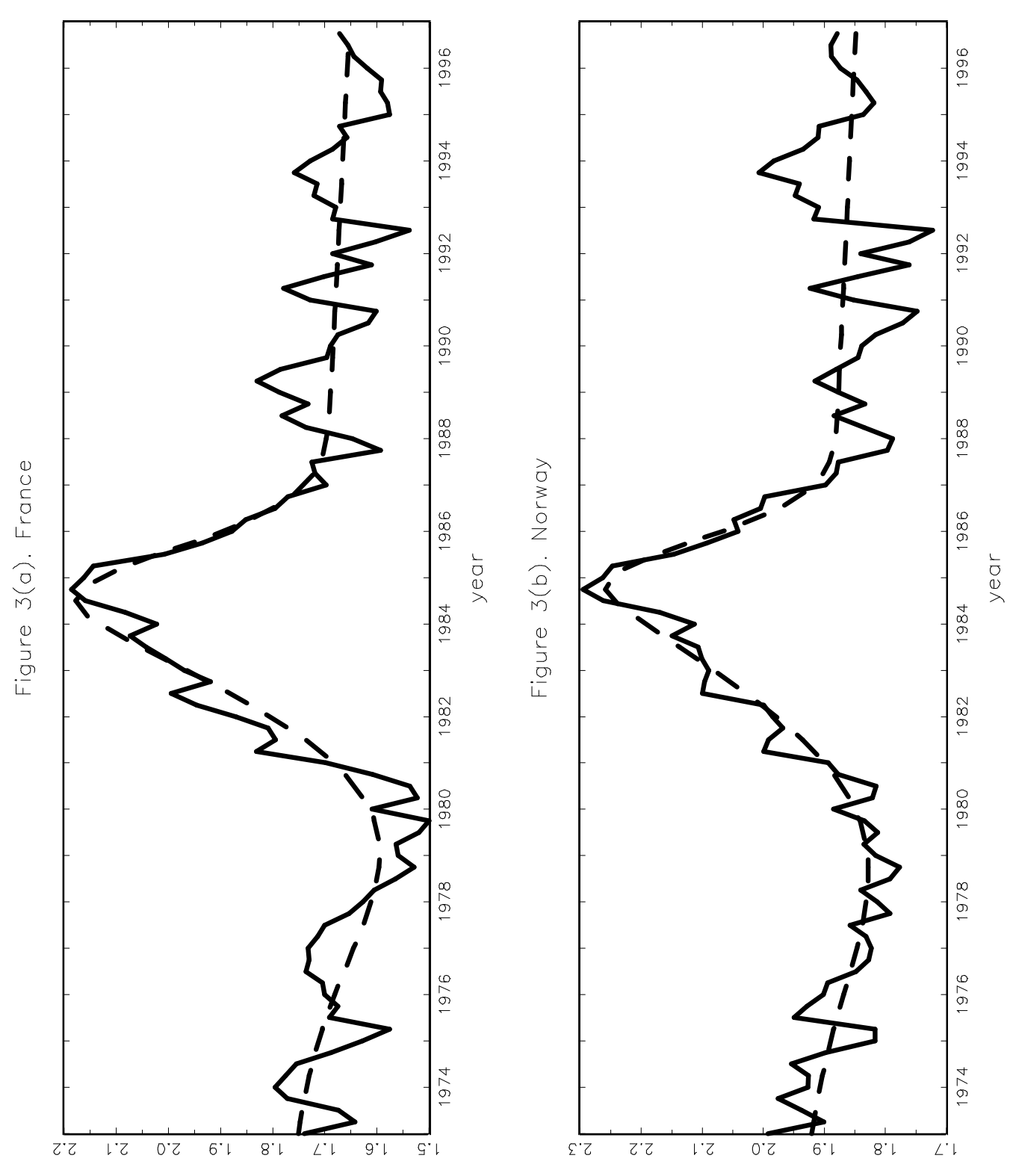